\title{
Taxonomic notes on Eustrophinae from the mid-Cretaceous Burmese amber, with description of a new species (Coleoptera, Tetratomidae)
}

\author{
Yun Hsiao ${ }^{1,2}$ (iD
}

Received: 29 April 2019 / Accepted: 10 June 2019 / Published online: 1 August 2019

(c) Paläontologische Gesellschaft 2019

\begin{abstract}
A new polypore fungus beetle species Allostrophus Hsiao, Ślipiński, Yu, Deng and Pang embedded in Upper Cretaceous Burmese amber (Cenomanian, ca. $99 \mathrm{Ma}$ ) is described: A. yangi sp. nov.; this new species can be differentiated from its only congener based on its antennomere 11 and fusiform, elongate body. Morphological characters preserved in the inclusion compared to A. cretaceus Hsiao, Ślipiński, Yu, Deng and Pang provide further data for completing the definition of Allostrophus. This new discovery highlights the species diversity of fungivorous beetles during the Cretaceous period, adding evidence that the formerly hypothesized co-diversification between fungus-feeding coleopterans and their food resources originated in the late Mesozoic Era.
\end{abstract}

Keywords Polypore fungus beetle $\cdot$ Allostrophus $\cdot$ Upper Cretaceous · Burmite inclusion · Taxonomy

\section{Introduction}

Polypore fungus beetles (Tetratomidae) are small and littleknown mycophagous beetles, comprising about 150 extant species belonging to 13 genera in five subfamilies (Nikitsky 1998), feeding on the fresh or softer fruiting bodies of various fungi. Eustrophinae Gistel, 1856 consists of five extant genera and 87 species distributed worldwide excluding Australia and New Zealand (Lawrence and Leschen 2010; Pollock 2012; Saitõ and Konvička 2017). The fossil records of Eustrophinae comprise four species from Cretaceous amber deposits (Soriano et al. 2014; Cai et al. 2016; Yu et al. 2016; Hsiao et al. 2018).

Herein, a new eustrophine species of Allostrophus Hsiao, Ślipiński, Yu, Deng and Pang, 2018 is described based on a well-preserved Upper Cretaceous amber (ca. $99 \mathrm{Ma}$ ) inclusion from Myanmar, which exhibits close affinities to $A$.

Handling Editor: Mike Reich.

Yun Hsiao

yunhsiao@outlook.com

1 Australian National Insect Collection, CSIRO National Research Collections Australia, Canberra, Australia

2 Division of Ecology and Evolution, Research School of Biology, The Australian National University, Canberra, Australia cretaceus Hsiao, Ślipiński, Yu, Deng and Pang, 2018. The well-preserved characters in this Burmite inclusion provide further information to complete the generic definition. Allostrophus is therefore redefined, based on the morphological comparison between the two known species.

\section{Materials and methods}

The specimen is included in a small, irregular quadrilateral piece of clear-yellow Burmese amber $(8.0 \times 5.0 \times 3.0 \mathrm{~mm})$ originating from amber deposits in the Hukawng Valley, Kachin, northern Myanmar (see details in Cruickshank and Ko 2003; Ross et al. 2010). The morphological characters of this amber fossil inclusion are well-preserved for taxonomic attribution. The beetle fossil is originally part of the author's private collection, but has now been deposited in the collections of the National Museum of Natural Science (NMNS), Taichung, Taiwan. Specimens of extant Eustrophinae used for comparison are deposited in the Australian National Insect Collection (ANIC), Commonwealth Scientific and Industrial Research Organisation (CSIRO), Canberra, Australia.

Burmese amber is one of the most important fossil resins and is renowned for yielding rich and exquisitely preserved arthropods, with over 1200 described species (Ross $2019 \mathrm{a}, \mathrm{b})$, and the age of the amber deposits is generally 
considered to be of the Late Cretaceous (earliest Cenomanian, $98.79 \pm 0.62 \mathrm{Ma}$ ) based on recently conducted $\mathrm{U}-\mathrm{Pb}$ zircon dating (Grimaldi et al. 2002; Shi et al. 2012).

The method for preparing the fossil-containing amber and measurements follows that of Hsiao et al. (2017). Observations of the specimen were performed using a Leica M205 C microscope. Photographs were taken using a Leica DFC500 digital camera mounted on a Leica M205 C microscope, and source images were then aligned and stacked in the Leica Application Suite (LAS) v4.9 software program. The morphological terminology follows Lawrence et al. (2011), and the classification of subfamilies and tribes of Tetratomidae follows Nikitsky (1998). The nomenclatural acts established herein are registered under ZooBank LSID urn:Isid:zoobank. org:pub:5DE4CC0E-D433-4D8D-B853-6F8C07262E81.

Abbreviations. ANIC-Australian National Insect Collection, CSIRO, Canberra, Australia; NMNS-National Museum of Natural Science, Taichung, Taiwan.

\section{Systematic palaeontology}

Order Coleoptera Linnaeus, 1758

Family Tetratomidae Billberg, 1820

Subfamily Eustrophinae Gistel, 1856

Tribe Eustrophini Gistel, 1856

Genus Allostrophus Hsiao, Ślipiński, Yu, Deng and Pang, 2018

Type species. A. cretaceus Hsiao, Ślipiński, Yu, Deng and Pang, 2018, from the Upper Cretaceous amber deposit of northeastern Myanmar, by monotypy.

Emended diagnosis (after Hsiao et al. 2018). Body approximately $3.0 \mathrm{~mm}$ long, oblong-oval to fusiform, dorsal surface covered with very dense and fine setae; eyes nearly contiguous dorsally; antenna sparsely tomentose, extending to basal one-sixth to one-fifth of elytra; antennomere 4 slightly broadened and 5-11 distinctly broadened, 4 long-triangular, 5 subtriangular, 6-10 subquadrate, 11 fusiform, narrowed distally; pronotum semicircular, with disc flattened; prosternal process narrowed distally, not extending to posterior margin of procoxae; each elytron with 8-9 regular rows of punctures; prothoracic episterna each with transverse suture; legs slender, with outer edges of meso- and metatibiae provided with scattered spines, without ridges.

Allostrophus yangi sp. nov.

Figures 1, 2, 3, 4
ZooBank LSID. urn:lsid:zoobank.org:act: 79F54EAB-E926-4776-9DAE-E57A641B0864.

Etymology. The specific name is given in honor of the author's advisor, Prof. Ping-Shih Yang (Dept. of Entomology, National Taiwan University), for his contribution to the development of entomology and promoting the public recognition of amber art pieces and studies of amber inclusions in Taiwan.

Holotype. No. YH-COL00001, deposited in NMNS; female, complete and well-preserved adult.

Type locality. Hukawng Valley, Kachin State, northern Myanmar.

Type stratum. Burmese amber (earliest Cenomanian, ca. $99 \mathrm{Ma}$; Shi et al. 2012).

Comparison. Allostrophus yangi can be easily distinguished from A. cretaceus by its antennomere 11, which is gradually narrowed distally (strongly narrowed in apical half in A. cretaceus) and fusiform, more slender and elongate elytra (oblong-oval, broader and more rounded in A. cretaceus).

Description.

Body (Fig. 1)-fusiform, narrowed posteriorly; cuticle black throughout. Body surface densely and finely covered with pubescence. Head length: $0.50 \mathrm{~mm}$, width: $0.50 \mathrm{~mm}$; antennal length: $1.20 \mathrm{~mm}$; pronotal length: $1.10 \mathrm{~mm}$, width: $1.10 \mathrm{~mm}$; elytra length: $2.20 \mathrm{~mm}$, width: $1.10 \mathrm{~mm}$.

Head (Fig. 2a, b) —small, strongly declined, not constricted posteriorly. Eyes large, laterally protruding, nearly contiguous, shallowly emarginate; surface coarsely faceted, with intrafacetal setae. Antennal insertions exposed dorsally; subantennal groove absent. Labrum transverse, somewhat rounded anteriorly; frontoclypeal suture absent. Antennae (Fig. 2c) 11-segmented, clubbed, with antennomere 4 slightly broadened and 5-11 distinctly broadened, surface sparsely tomentose, when directed backwards extending to basal one-sixth to one-fifth of elytra; scape cylindrical; pedicel short, antennomeres 3-4 long-triangular, 5 subtriangular, 6-10 subquadrate, 11 fusiform, gradually narrowed distally, with pointed apex. Mandibles short and broad. Each maxillary palpus four-segmented, apical palpomere slender, apical margin sharp, terminal angle slightly obliquely truncate.

Pronotum (Fig. 2d)—semicircular, narrowed anteriorly, posterior edge bisinuate, moderately produced forming obtuse, shallowly emarginate mesal lobe, length nearly as long as width, ca 2.2 times as wide as head; lateral pronotal carinae 
Fig. 1 Habitus (YH-COL00001) of Allostrophus yangi sp. nov., holotype. a Left lateral view; b right lateral view. Scale bar $0.5 \mathrm{~mm}$

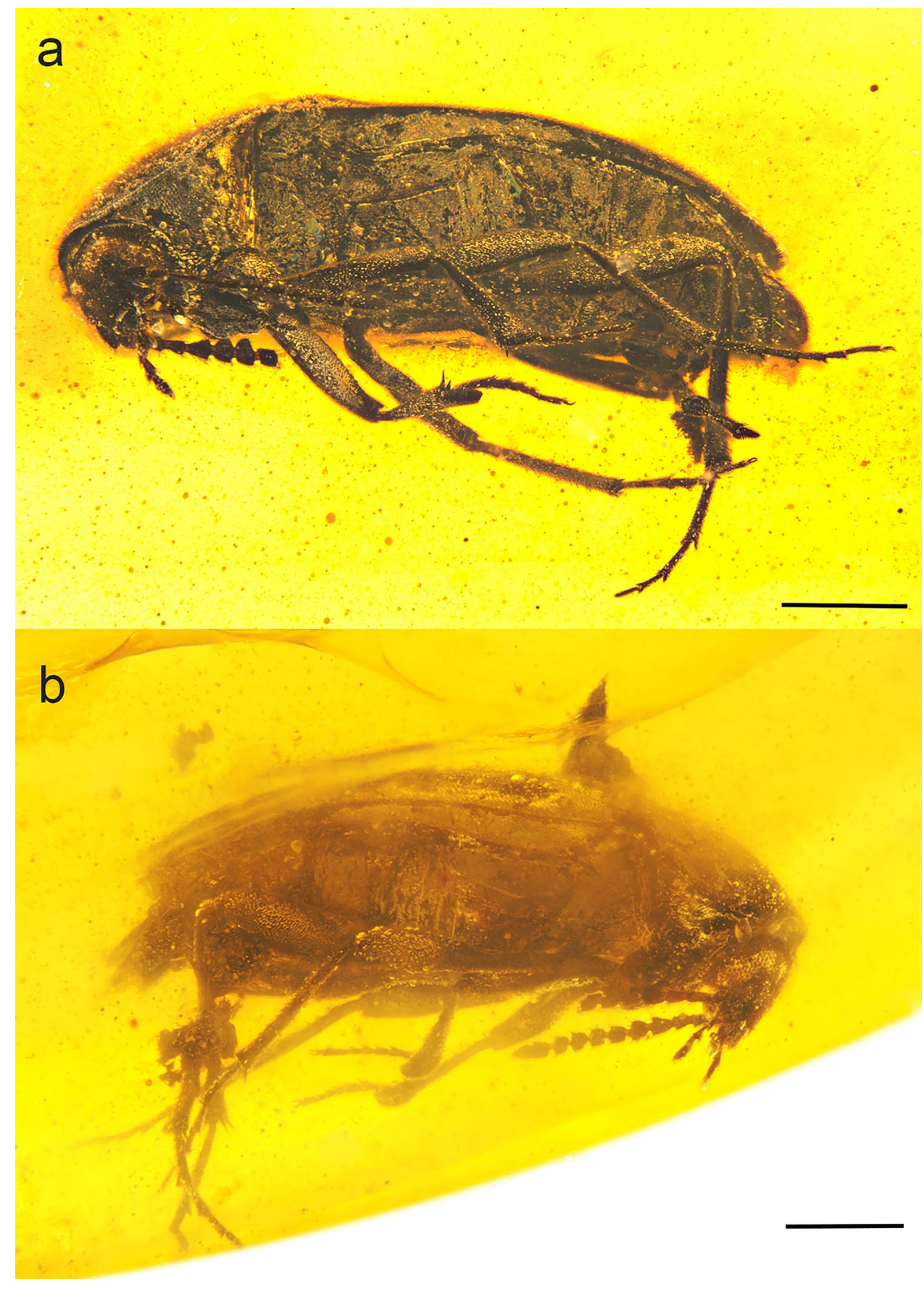

complete, visible from above; anterior angles not produced forward, posterior angles obtuse; disc flattened, with two very weak subbasal impressions. Prosternum before coxae shorter than shortest diameter of procoxal cavity. Prosternal process short, narrowed anteriorly, ending before posterior edges of coxae. Prothoracic episterna each with transverse suture (Fig. 2e). Each procoxal cavity strongly transverse, externally broadly open. Scutellar shield small, narrowed posteriorly, with obtuse apex.
Elytra (Fig. 3a, b)—elongate, narrowing posteriorly, apex rounded, as wide as pronotal width at humeri, length ca 2.0 times width and ca 2.0 times pronotal length; each elytral disc with nine regular rows of punctures, distance between elytral striae ca $0.08 \mathrm{~mm}$, interspaces between punctures along elytral striae 1-2 times wider than puncture diameter. Mesoventrite (Fig. 3c) medially carinate, short. Mesocoxal cavities rounded, narrowly separated, open laterally to mesepimera. Metaventrite (Fig. 3c) with complete, long and grooved discrimen. Metanepisterna distinctly subdivided into a short triangular anterior and an elongate-quadrangular 
Fig. 2 Enlargements (YHCOL00001) of Allostrophus yangi sp. nov., holotype. a Head, dorsal view; b head, lateral-frontal view; c antenna; d pronotum; e prothorax, prosternal process and transverse suture on prothoracic episternum indicated by dark red arrows. Scale bars $0.2 \mathrm{~mm}$ in (a, b, c), $0.5 \mathrm{~mm}$ in $(\mathbf{d}, \mathbf{e})$

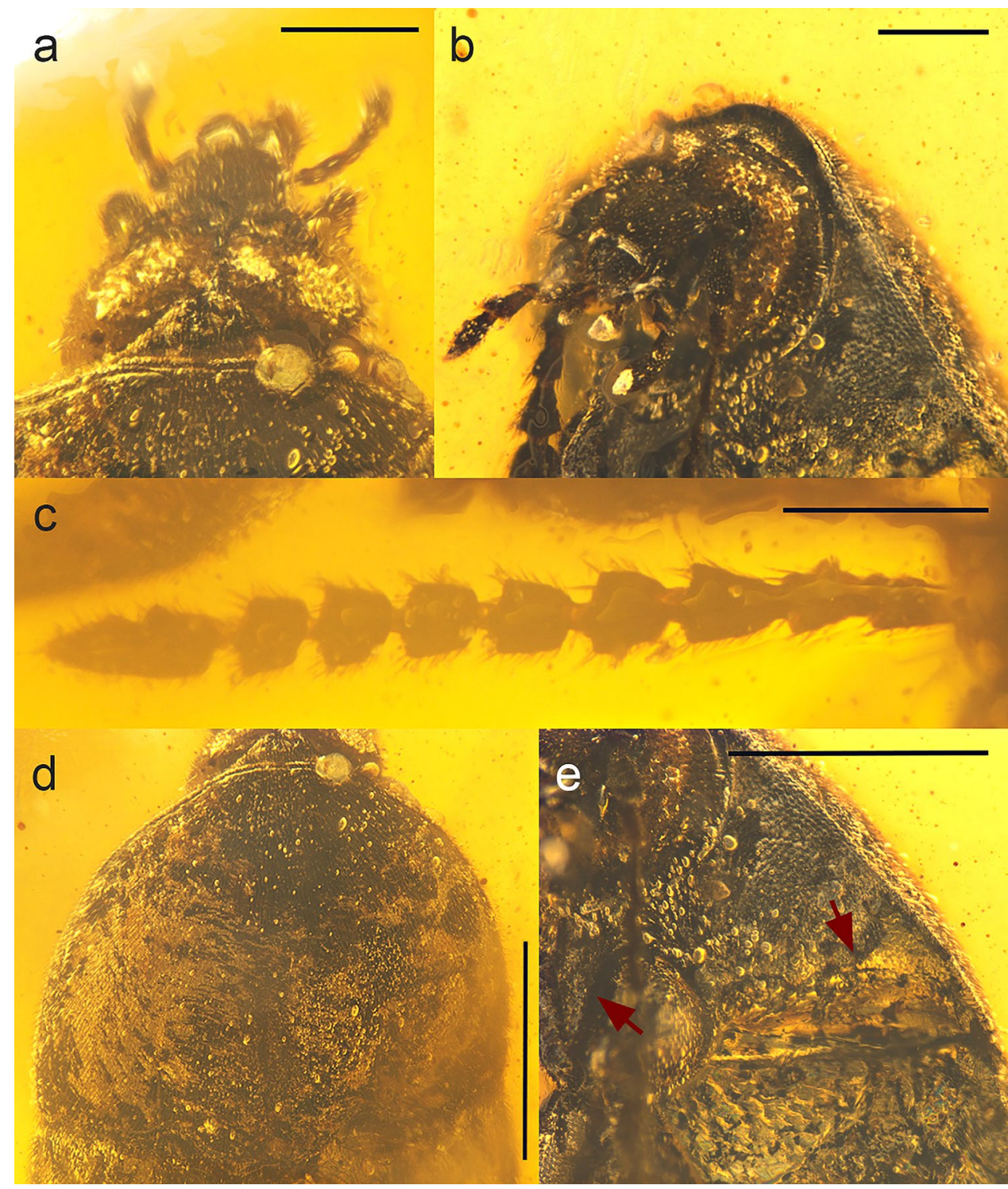

posterior piece. Metacoxae transverse, narrowly separated, obliquely oriented, not extending laterally to meet elytra; coxal plates absent.

Abdomen (Fig. 3d) — with five ventrites, broadly oval, linearly narrowed posteriorly, with rounded apex. Ventrite 1 without postcoxal line.

Legs—slender. Tibiae elongate, terminated by dense row of regular, thin, spiniform setae and short paired tibial spurs (Fig. 4a); outer edge of protibia (Fig. 4b) with short, closely set spines; outer edges of meso- and metatibia (Figs. 4c, d) with stout, scattered spines. Tarsal formula 5-5-4; tarsomeres simple, without ventral lobes; pro-, meso- and metatarsi each with a circle of spines at apex of tarsomeres 1-4, 1-4 and 1-3, respectively (Fig. 4a); pretarsal claws simple, sharp. Empodial setae very short.
Ovipositor-with paired, short, subcylindrical styli (Fig. 3d).

\section{Discussion}

The fossil beetle described herein belongs to Tetratomidae and Eustrophinae based on the following diagnostic characters: body small, oblong-oval, narrowed posteriorly; antennae gradually clubbed; pronotum with paired, weak subbasal impressions; scutellum simple; 8-9 traces of elytral striae; tarsi simple, narrow; metatibial spurs short. The narrowly separated, almost dorsally contiguous eyes, distinct elytral striae, and smooth outer faces of meso- and metatibiae further warrant its placement within Eustrophini. This polypore fungus beetle is closely related to Allostrophus cretaceus by sharing small, dorsally densely and finely pubescent body; 
Fig. 3 Enlargements (YHCOL00001) of Allostrophus yangi sp. nov., holotype. a

Elytra, right lateral view; b elytra, left lateral view; c mesoand metaventrite; $\mathbf{d}$ abdomen, styli of ovipositor indicated by dark red arrow. Scale bar $0.5 \mathrm{~mm}$

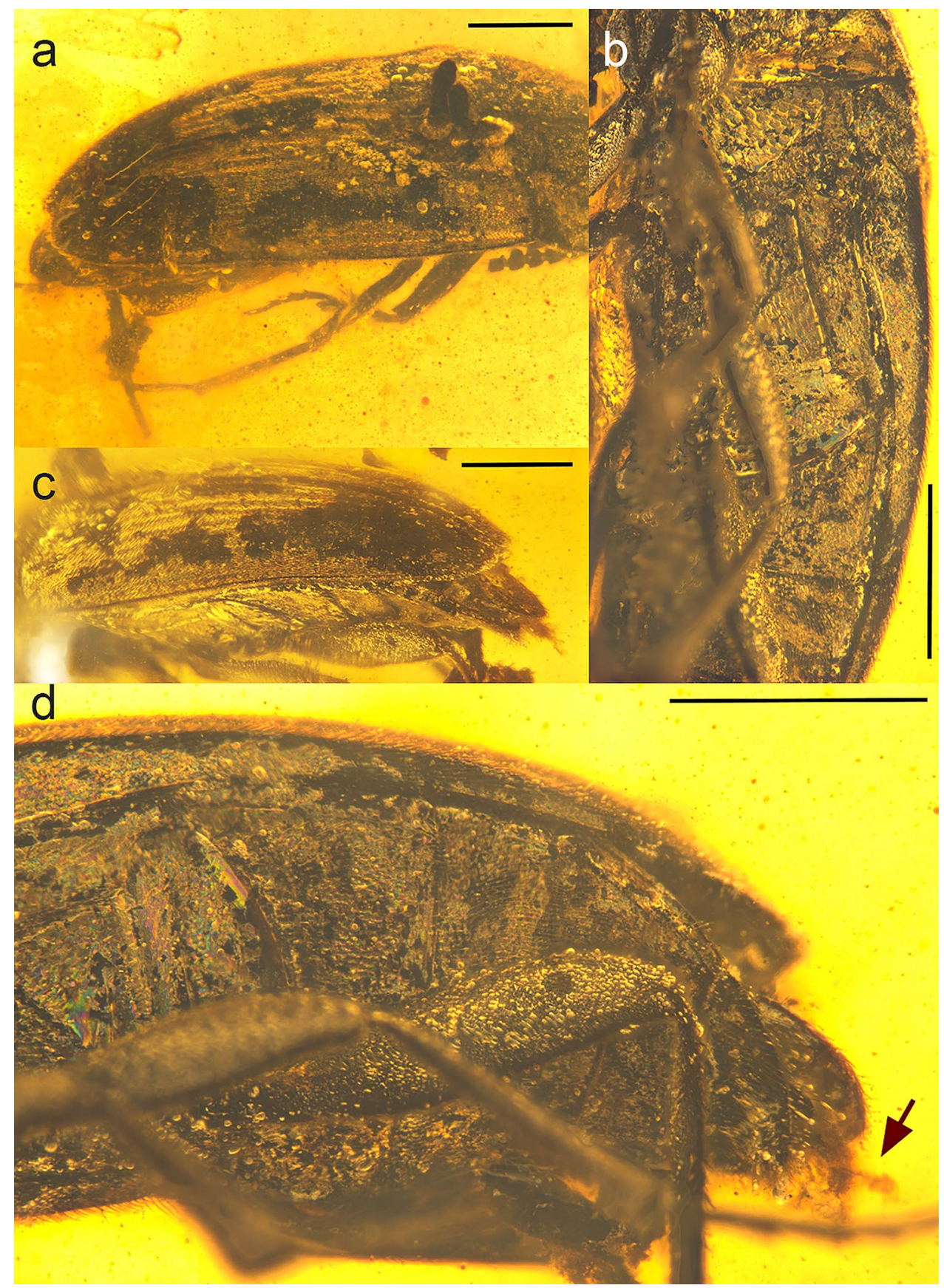

nearly contiguous eyes; gradually clubbed antennae; semicircular and flattened pronotum; distinct elytral striae; smooth surface of meso- and metatibiae, with scattered spines at the outer edges. Therefore, this new fossil tetratomid beetle should be assigned to the genus Allostrophus. It seems plausible that both species could be conspecific and A. yangi sp. nov. is an intraspecific variation of A. cretaceus. Nonetheless, the diagnostic differences between the species are consistent with those used to separate extant tetratomid species, and thus we consider them to delimit two valid species.
The type species of Allostrophus, A. cretaceus, bears a considerable resemblance to extant eustrophines, especially Synstrophus Seidlitz, 1898, by similar large, dorsally contiguous eyes; distinctly broadened antennomeres 5-11; distinct elytral striae; and smooth outer faces of meso- and metatibiae, without oblique, comb-like ridges. However, due to its preservation condition, diagnostic ventral characters such as prosternal process and prothoracic episternum are largely unrecognizable, leaving the question of relationships between the two genera open. Fortunately, $A$. yangi preserves clear structure of the prosternal process and 
Fig. 4 Enlargements (YHCOL00001) of Allostrophus yangi sp. nov., holotype. a Protibial apex and tarsomeres, $\mathbf{b}$ protibia, c mesotibia, $\mathbf{d}$ metatibia. Scale bar $0.2 \mathrm{~mm}$
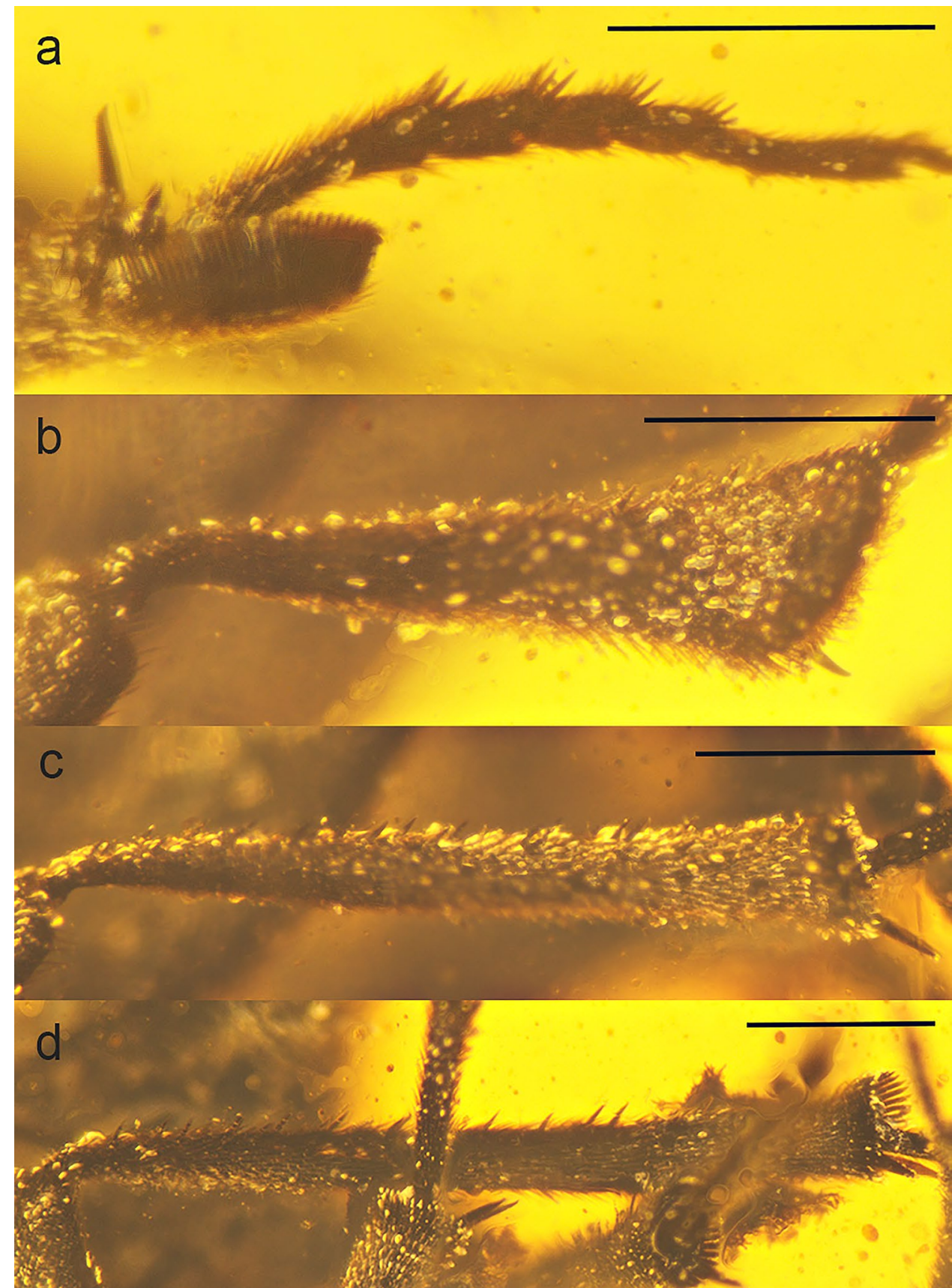

transverse suture on the prothoracic episternum, which are identical to Synstrophus, supporting the tentative affinity between Allostrophus and Synstrophus.

Recent molecular phylogenetic studies have revealed that the major groups of mushrooms diversified by the Early Cretaceous (Taylor and Berbee 2006; Floudas et al. 2012), and highly diverse Agaricomycetes from Burmese amber also indicate the evolutionary radiation of gilled mushrooms during the mid-Cretaceous (Cai et al. 2017). The new discovery represents the sixth documented record of Tetratomidae during the Cretaceous Period, indicating diversification of mycophagous beetles by the Late Mesozoic. The paleodiversity of fungus-feeding coleopterans undoubtedly strengthens the previously hypothesized synchronous diversification between an early fungivore functional group of beetles and their host fungi (Hsiao et al. 2018).

Acknowledgements I wish to express my heartfelt thanks to Dr. Rolf Oberprieler (ANIC, CSIRO, Australia), Dr. Chia-Lung Huang and Ms. Ying-Han Wang for various assistance, and to the Editor-in-Chief, Dr. Mike Reich (Munich, Germany), and Prof. Daniel K. Young (University of Wisconsin-Madison, USA) and Prof. Darren A. Pollock 
(Eastern New Mexico University, USA) for their valuable suggestions in improving an earlier version of the manuscript.

\section{References}

Billberg, G.J. 1820. Enumeratio insectorum in Museo Gust. Joh. Billberg. Stockholm: Typis Gadelianis.

Cai, C., Y. Hsiao, and D. Huang. 2016. A new genus and species of polypore fungus beetle in Upper Cretaceous Burmese amber (Coleoptera, Tetratomidae, Eustrophinae). Cretaceous Research 60: 275-280.

Cai, C., R.A.B. Leschen, D.S. Hibbett, F. Xia, and D. Huang. 2017. Mycophagous rove beetles highlight diverse mushrooms in the Cretaceous. Nature Communications 8: 14894.

Cruickshank, R.D., and K. Ko. 2003. Geology of an amber locality in the Hukawng Valley, northern Myanmar. Journal of Asian Earth Sciences 21: 441-455.

Floudas, D., M. Binder, R. Riley, K. Barry, R.A. Blanchette, B. Henrissat, A.T. Martínez, R. Otillar, J.W. Spatafora, J.S. Yadav, A. Aerts, I. Benoit, A. Boyd, A. Carlson, A. Copeland, P.M. Coutinho, R.P. de Vries, P. Ferreira, K. Findley, B. Foster, J. Gaskell, D. Glotzer, P. Górecki, J. Heitman, C. Hesse, C. Hori, K. Igarashi, J.A. Jurgens, N. Kallen, P. Kersten, A. Kohler, U. Kües, T.K. Kumar, A. Kuo, K. LaButti, L.F. Larrondo, E. Lindquist, A. Ling, V. Lombard, S. Lucas, T. Lundell, R. Martin, D.J. McLaughlin, I. Morgenstern, E. Morin, C. Murat, L.G. Nagy, M. Nolan, R.A. Ohm, A. Patyshakuliyeva, A. Rokas, F.J. Ruiz-Dueñas, G. Sabat, A. Salamov, M. Samejima, J. Schmutz, J.C. Slot, F. St John, J. Stenlid, H. Sun, S. Sun, K. Syed, A. Tsang, A. Wiebenga, D. Young, A. Pisabarro, D.C. Eastwood, F. Martin, D. Cullen, I.V. Grigoriev, and D.S. Hibbett. 2012. The Paleozoic origin of enzymatic lignin decomposition reconstructed from 31 fungal genomes. Science 336: $1715-1719$.

Gistel, J. 1856. Die Mysterien der europäischen Insectenwelt. Kempten: T. Dannheimer.

Grimaldi, D.A., M.S. Engel, and P.C. Nascimbene. 2002. Fossiliferous Cretaceous amber from Myanmar (Burma): its rediscovery, biotic diversity, and paleontological significance. American Museum Novitates 3361: 1-72.

Hsiao, Y., A. Ślipiński, C. Deng, and H. Pang. 2017. A new genus and species of soldier beetle from Upper Cretaceous Burmese amber (Coleoptera, Cantharidae, Malthininae). Cretaceous Research 69: 119-123.

Hsiao, Y., A. Ślipiński, Y. Yu, C. Deng, and H. Pang. 2018. Allostrophus cretaceus gen. et sp. nov.: A new polypore fungus beetle (Coleoptera, Tetratomidae) from the Cretaceous Myanmar amber. Cretaceous Research 92: 195-200.
Lawrence, J.F., and R.A.B. Leschen. 2010. Tetratomidae Billberg, 1820. In Coleoptera, Beetles, Handbuch der Zoologie/Handbook of Zoology, vol. 2, eds. R.A.B. Leschen, R.G. Beutel, and J.F. Lawrence, 514-520. Berlin: Walter de Gruyter Inc.

Lawrence, J.F., A. Slipinski, A.E. Seago, M.K. Thayer, A.F. Newton, and A.E. Marvaldi. 2011. Phylogeny of the Coleoptera based on morphological characters of adults and larvae. Annales Zoologici 61: $1-217$.

Linnaeus, C. 1785. Systema naturae per regna tria naturae, secundum classes, ordines, genera, species, cum characteribus, differentiis, synonymis, locis, Editio decima, reformata, Tomus I. Holmiae: Laurentii Salvii.

Nikitsky, N.B. 1998. Generic classification of the beetle family Tetratomidae (Coleoptera, Tenebrionoidea) of the world, with description of new taxa. Sofia-Moscow: Pensoft Publishers.

Pollock, D.A. 2012. Review of the Eustrophinae (Coleoptera, Tetratomidae) of America north of Mexico. ZooKeys 188: 1-153.

Ross, A., C. Mellish, P. York, and B. Crighton. 2010. Burmese amber. In Biodiversity of fossils in amber from the major world deposits, ed. D. Penney, 208-235. Manchester: Siri Scientific Press.

Ross, A.J. 2019a. Burmese (Myanmar) amber checklist and bibliography 2018. Palaeoentomology 2: 22-84.

Ross, A.J. 2019b. Burmese (Myanmar) amber taxa, on-line supplement v.2019.1., 1-20. http://www.nms.ac.uk/explore/stories/natur al-world/burmese-amber/. Accessed 18 June 2019.

Saitõ, M., and O. Konvička. 2017. A new species of Holostrophus (Paraholostrophus) (Coleoptera: Tetratomidae) from central Honshu island, Japan. Acta Musei Silesiae, Scientiae Naturales 66: 1-5.

Seidlitz, G. von. 1898. Melandryidae. In Naturgeschichte der Insecten Deutschlands. Begonnen von Dr. W.F. Erichson, fortgesetzt von Prof. Dr. H. Schaum, Dr. G. Kraatz, H. v. Kiesenwetter, Julius Weise, Edm. Reitter und Dr. G. Seidlitz. Erste Abteilung Coleoptera. Fünfter Band. Zweite Hälfte. Berlin: Nicolaische Verlags-Buchhandlung.

Shi, G., D.A. Grimaldi, G.E. Harlow, J. Wang, J. Wang, M. Yang, W. Lei, Q. Li, and X. Li. 2012. Age constraint on Burmese amber based on U-Pb dating of zircons. Cretaceous Research 37: 155-163.

Soriano, C., D. Pollock, D. Neraudeau, A. Nel, and P. Tafforeau. 2014. First fossil record of polypore fungus beetles from Lower Cretaceous amber of France. Acta Palaeontologica Polonica 59: 941-946.

Taylor, J.W., and M.L. Berbee. 2006. Dating divergences in the fungal tree of life: review and new analyses. Mycologia 98: 838-849.

Yu, Y., Y. Hsiao, A. Ślipiński, J. Jin, D. Ren, and H. Pang. 2016. A new Late Cretaceous genus and species of polypore fungus beetles (Coleoptera, Tetratomidae) from northern Myanmar. Cretaceous Research 68: 34-39. 